\title{
Dimethylglyoxime as an efficient ligand for copper-catalyzed hydroxylation of aryl halides
}

\author{
SURESH S SHENDAGE* \\ Department of Chemistry, KET'S Vinayak Ganesh Vaze College of Arts, Science and Commerce, \\ Mithagar Road, Mulund (E), Mumbai, Maharashtra 400 081, India \\ E-mail: sureshsshendage@gmail.com
}

MS received 21 September 2017; revised 1 December 2017; accepted 9 December 2017; published online 7 February 2018

\begin{abstract}
The CuI/dimethylglyoxime (CuI/DMG) catalyzed direct hydroxylation of aryl iodides with $\mathrm{CsOH}$ takes place at $120^{\circ} \mathrm{C}$ in a mixed solvent system (DMSO- $\mathrm{H}_{2} \mathrm{O}, 1: 1$ ), afforded the corresponding phenols in good to excellent yield. Aryl bromides are found to be less reactive than aryl iodides under these reaction conditions.
\end{abstract}

Keywords. Aryl halide; C-O coupling; dimethyl glyoxime; hydroxylation; phenol.

\section{Introduction}

Phenols play key role in production of natural products, pharmaceutical and medicinal compounds, as well as in polymers and other materials. These days, about more than $90 \%$ of the world's phenol requirement is satisfied by the Hock process, which entail the peroxidation of cumene, itself obtained from benzene propylation. ${ }^{1-4}$ The conventional methods used in synthesis of phenols are nucleophilic aromatic substitution of activated aryl halides, ${ }^{5}$ benzyne procedure, ${ }^{6}$ and copper-mediated transformation of arene diazonium salts. ${ }^{7}$ Recently, various efficient palladium/phosphine-catalyzed protocols have been developed for the formation of phenols. ${ }^{8,9}$ However, less expensive copper (I) salt as catalyst would be most attractive option for economic benefits and low toxicity issues. The usage of a cheaper system facilitates the hydroxylation ${ }^{10,11}$ of aryl halides have turn out to be an important objective. In organic synthesis the development of a mild, general and highly efficient method for the preparation of phenols is a challenging task. At present the availability of starting materials and the direct nucleophilic substitution of a halogen atom in aryl halides are interesting strategies for the preparation of substituted phenols. These days copper-catalyzed hydroxylation of aryl halides has gained considerable attention. In the past it was reported that direct crosscoupling of hydroxide salts and aryl

\footnotetext{
*For correspondence
}

iodides using $\mathrm{CuI}$ and either 1, 3-diketone ${ }^{3}$ or 1, 10phenanthroline $^{12}$ in aqueous DMSO can be used for synthesis of phenols. In addition to this several other ligands such as lithium pipecolinate, tetrabutylammonium hydroxide pentahydrate, 8-hydroxyquinoline-N-oxide and D-glucose ${ }^{11,13-15}$ were used, which shows that ligands play important role in the activity of catalyst. However, in spite of these advancements, there is a need for economical and easily available ligands which have general applicability. Copper catalyzed route is essential from an industrial perspective, owing to the availability of reagents, low cost and low toxicity. ${ }^{16,17}$

This paper reports a simple, practical and efficient copper-catalyzed synthesis of substituted phenols from aryl halides by using dimethyl glycoxime (Butane-2, 3dione dioxime) as an inexpensive, simple, and efficient ligand in presence of $\mathrm{CsOH}$ base. Thus, dimethylglyoxime has drawn considerable interest from both the chemical and biological sciences. The oxime group $(>\mathrm{C}=\mathrm{N}-\mathrm{OH}$ ), which perhaps considered to be derived from oxy-imine, is amphoteric since it contains slightly basic nitrogen and mildly acidic hydroxyl groups. ${ }^{18}$

\section{Experimental}

All reagents were commercially purchased and used without further purification. The reation products were identified by comparing observed and reported ${ }^{1} \mathrm{H}-\mathrm{NMR}$ spectra and melting point. ${ }^{1} \mathrm{H}$ NMR spectra were recorded on a Bruker AC-400 (400 MHz) spectrometer with TMS as an internal Standard. 
<smiles>Ic1ccccc1</smiles><smiles>CCCCC</smiles><smiles>Oc1ccccc1</smiles>

Scheme 1. Copper catalyzed Hydroxylation of Aryl Halides.

\subsection{General procedure for the synthesis of substituted phenols}

The appropriate aryl halide ( $1 \mathrm{mmol}), \mathrm{CsOH}(3 \mathrm{mmol})$, and $\mathrm{H}_{2} \mathrm{O}(1 \mathrm{~mL})$ were added over $0.1 \mathrm{~h}$, to a stirred solution of CuI (19.0 mg, $10 \mathrm{~mol} \%)$ and Dimethylglyoxime (L6; $23.2 \mathrm{mg}, 20 \mathrm{~mol} \%)$ in DMSO (1 mL), and the reaction mixture was stirred at $120^{\circ} \mathrm{C}$ (aryl iodides) or (aryl bromides). The progress of the reaction was monitored by TLC (EtOAc-hexane). The reaction mixture was then cooled to room temperature and acidified with $0.5 \mathrm{M} \mathrm{HCl}(0.5 \mathrm{~mL})$. The resulting mixture was extracted with EtOAc $(3 \times 10 \mathrm{~mL})$ and dried $\left(\mathrm{Na}_{2} \mathrm{SO} 4\right)$. Evaporation of the solvent gave a residue that was purified by column chromatography.

\section{Results and Discussion}

Initially, the reaction conditions were optimized using iodobenzene as a model substrate and using different ligands, bases, copper salts and solvents (Table 1, entries 1-16). Among several ligands briefly screened, L6 (dimethylglyoxime) and L3 $(\mathrm{N}, \mathrm{N}, \mathrm{N}, \mathrm{N}$-Tetramethylethane-1,2-diamine) are effective. The ligand L6 gave
96\% (Table 1, entry 6) yield of the corresponding product higher than ligand L3 (85\%) (Table 1, entry 3). Hence the ligand L6 was identified as a competent ligand, whereas ligands L1(2,2-Bipyridine), L2(1,10Phenanthroline), L4[N-(2-cyanophenyl)benzamide] and L5 (2,2',2', $2^{\prime \prime \prime}$-(ethane-1,2-diylbis(azanetriyl)tetraacetic acid) afforded lower yield (Table 1, entries 1, 2, 4 $\& 5)$. In the absence of ligand, controlled experiments were carried out in order to check whether reaction proceeds in absence of ligand or not. It was found that only $15 \%$ yield of the desired product was obtained without the aid of the ligand (Table 1, entry 16).
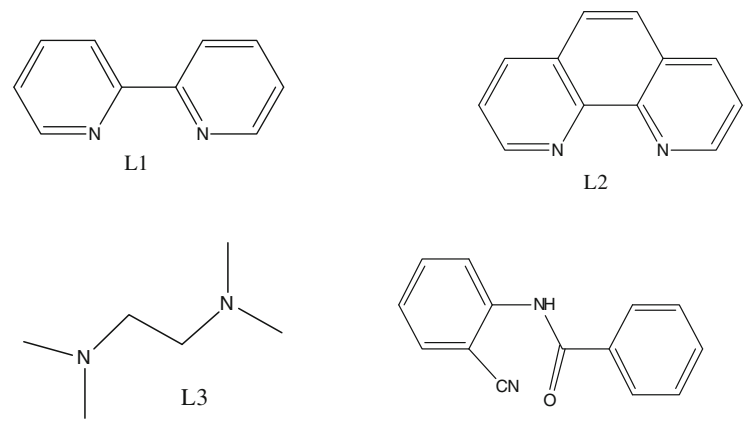

L4<smiles>O=C(O)CN(CCN(CC(=O)O)CC(=O)O)CC(=O)O</smiles><smiles>CC(=NO)C(C)=NO</smiles>

Table 1. Optimization of Hydroxylation of Aryl Halides ${ }^{\mathrm{a}}$.

\begin{tabular}{|c|c|c|c|c|c|}
\hline Sr. no & Ligand & Solvent [2ml] & Base & {$[\mathrm{Cu}]$ salts } & Yield ${ }^{\mathrm{b}}(\%)$ \\
\hline 1 & L1 & $\mathrm{DMSO} / \mathrm{H}_{2} \mathrm{O} 1: 1$ & $\mathrm{CsOH}$ & $\mathrm{CuI}$ & 72 \\
\hline 2 & L2 & $\mathrm{DMSO} / \mathrm{H}_{2} \mathrm{O} 1: 1$ & $\mathrm{CsOH}$ & $\mathrm{CuI}$ & 76 \\
\hline 3 & L3 & $\mathrm{DMSO} / \mathrm{H}_{2} \mathrm{O} 1: 1$ & $\mathrm{CsOH}$ & $\mathrm{CuI}$ & 85 \\
\hline 4 & L4 & $\mathrm{DMSO} / \mathrm{H}_{2} \mathrm{O} 1: 1$ & $\mathrm{CsOH}$ & $\mathrm{CuI}$ & 66 \\
\hline 5 & L5 & $\mathrm{DMSO} / \mathrm{H}_{2} \mathrm{O} 1: 1$ & $\mathrm{CsOH}$ & $\mathrm{CuI}$ & 35 \\
\hline 6 & L6 & $\mathrm{DMSO} / \mathrm{H}_{2} \mathrm{O} 1: 1$ & $\mathrm{CsOH}$ & $\mathrm{CuI}$ & 96 \\
\hline 7 & L6 & $\mathrm{DMSO} / \mathrm{H}_{2} \mathrm{O} 1: 1$ & $\mathrm{KOH}$ & $\mathrm{CuI}$ & 82 \\
\hline 8 & L6 & NMP & $\mathrm{CsOH}$ & $\mathrm{CuI}$ & 20 \\
\hline 9 & L6 & $\mathrm{DMF} / \mathrm{H}_{2} \mathrm{O} 1: 1$ & $\mathrm{CsOH}$ & $\mathrm{CuI}$ & No Reaction \\
\hline 10 & L6 & $\mathrm{H}_{2} \mathrm{O}$ & $\mathrm{CsOH}$ & $\mathrm{CuI}$ & 05 \\
\hline 11 & L6 & 1,4-dioxane $/ \mathrm{H}_{2} \mathrm{O}$ & $\mathrm{CsOH}$ & $\mathrm{CuI}$ & 32 \\
\hline 12 & L6 & DMSO & $\mathrm{CsOH}$ & $\mathrm{CuI}$ & 30 \\
\hline 13 & L6 & $\mathrm{DMSO} / \mathrm{H}_{2} \mathrm{O} 1: 1$ & $\mathrm{CsOH}$ & $\mathrm{CuCl}$ & 62 \\
\hline 14 & L6 & $\mathrm{DMSO} / \mathrm{H}_{2} \mathrm{O} 1: 1$ & $\mathrm{CsOH}$ & CuSO4 & 42 \\
\hline 15 & L6 & $\mathrm{DMSO} / \mathrm{H}_{2} \mathrm{O} 1: 1$ & $\mathrm{CsOH}$ & $\mathrm{Cu}(\mathrm{OAc})_{2}$ & 50 \\
\hline 16 & - & $\mathrm{DMSO} / \mathrm{H}_{2} \mathrm{O} 1: 1$ & $\mathrm{CsOH}$ & $\mathrm{CuI}$ & 15 \\
\hline
\end{tabular}

a Iodobenzene (1 mmol), Ligand (20 mol\%), CuI (10 mol\%).

b Isolated yield. 
Table 2. Copper(I)-Catalyzed Hydroxylation of Aryl Iodides and Bromides ${ }^{\mathrm{a}}$.

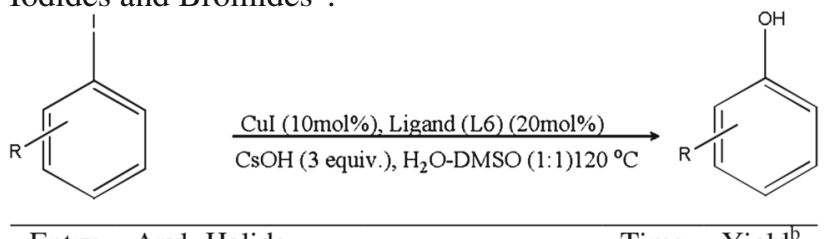

\begin{tabular}{|c|c|c|}
\hline Entry & Aryl Halide & Time \\
\hline
\end{tabular}$$
1
$$

4
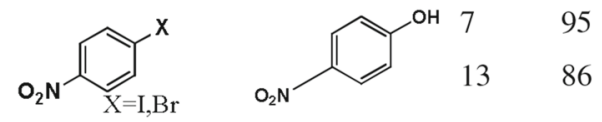

5

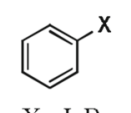

$\mathrm{X}=\mathrm{I}, \mathrm{Br}$<smiles>[X]c1ccc(Cl)cc1Br</smiles><smiles>Oc1ccccc1</smiles><smiles>CC(=O)c1ccc(O)cc1</smiles>

6

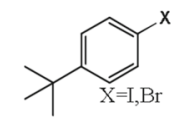<smiles>CC(C)(C)c1ccc(O)cc1</smiles>

10

8<smiles>[Y]c1ccc(Cl)c(Br)c1C</smiles><smiles>Cc1cc(Cl)ccc1O</smiles>

9<smiles>Cc1cccc(C)c1I</smiles><smiles>Cc1cccc(C)c1O</smiles>

10
10

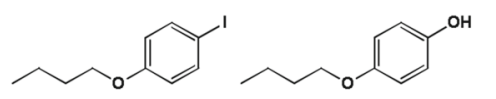

11
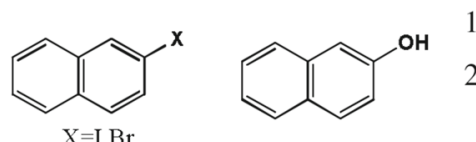

12
20
${ }^{a}$ Reaction conditions: Aryl iodide ( $\left.1 \mathrm{mmol}\right), \mathrm{CuI}(10 \mathrm{~mol} \%)$, DMG(L6; $20 \mathrm{~mol} \%), \mathrm{CsOH}$ (3 equivalent), DMSO/ $\mathrm{H}_{2} \mathrm{O}$ (1:1; $2 \mathrm{~mL}), 120^{\circ} \mathrm{C} .{ }^{\mathrm{b}}$ Isolated yield.
Among the bases, potassium hydroxide and cesium hydroxide, the latter provided the best results (Table 1, entries 6 \& 7). A 1:1 mixture of $\mathrm{DMSO} / \mathrm{H}_{2} \mathrm{O}$ was found to be the suitable solvent for this reaction. Solvents such as NMP, water, $\mathrm{DMF} / \mathrm{H}_{2} \mathrm{O}(1: 1)$ and 1,4-dioxane/ $\mathrm{H}_{2} \mathrm{O}$ (Table 1, entries 8-12) were found to be less effective, providing the desired product in less than $32 \%$. In addition, other copper salts such as $\mathrm{CuCl}, \mathrm{CuSO}_{4}$ and $\mathrm{Cu}(\mathrm{OAc})_{2}$ were poorer. The optimum temperature was $120^{\circ} \mathrm{C}$ (Scheme 1).

The scope of the CuI/DMG catalyzed synthesis of phenols was then investigated under above optimized conditions. Irrespective of the aryl iodides as electronrich, electron-poor, or sterically bulky, all of them afforded good to excellent yields (Table 2, entries 111) of the corresponding products in presence of $\mathrm{CsOH}$ in DMSO $/ \mathrm{H}_{2} \mathrm{O}(1: 1)$. The hydroxylation of iodobenzene went on smoothly in high yields (96\%) (Table 2, entry 6). In case of the activated aryl iodides, such as Nitro, carbonyl (Table 2, entries $3 \& 4$ ) the reactions proceeded in $7 \mathrm{~h}$ providing the products in 94 \& $95 \%$ yield. In addition to this, high yields observed in the reaction of 4-methoxyphenyl, 4-butoxyphenyl and 4-t-butylphenyl (Table 2, entries 6, 7 and 10). Furthermore, 2-Iodonaphthalene gave $90 \%$ yield in $12 \mathrm{~h}$. However, chloro substituted iodobenzene provided $89 \%$ yield of the corresponding product (Table 2 , entry 2).

The reaction conditions were further investigated for the hydroxylation of the less reactive aryl bromides, most of the aryl bromides were smoothly converted into the corresponding phenols (Table 2, entries 1-8). Bromobenzene underwent hydroxylation to give the phenol with $85 \%$ yield, but required 17 h (Table 2, entry 1). However, the CuI/DMG system were able to tolerate some functional groups such as t-butyl, carbonyl, methyl, t-butoxide, nitro, and methoxy groups but showed lower yield of the corresponding products, compared to aryl iodides (Table 2, entries 3-7 and 10). Moreover, 2-bromonaphathalene afforded $80 \%$ yield in $20 \mathrm{~h}$ (Table 2, entry11). This protocol has advantages such as short reaction time and low reaction temperature over earlier reported methods.

\section{Conclusion}

This paper reports use of dimethylglyoxime (L6) as a simple, efficient and economical ligand for the direct copper-catalyzed synthesis of phenols. This protocol tolerates various substituted and unsubstituted aryl iodides and aryl bromides. The present protocol could 
be used for synthesis of various substituted phenols. In general, the lower cost of copper and the use of readily available ligands offer undisputable advantages over the expensive metal/ligand systems. The reported protocol will attract much attention in research because of their wide applications in pharmaceuticals, polymers and natural products.

\section{Supplementary Information (SI)}

${ }^{1} \mathrm{HNMR},{ }^{13} \mathrm{C}$ NMR and GC-MS spectral data for compounds dealt in this article can be accessed at www.ias.ac.in/chemsci.

\section{Acknowledgements}

The author is thankful to KET'S V. G. Vaze College for financial support. The author is also thankful SAIF, IIT Mumbai for Mass and Instrumentation department Solapur University, Solapur for ${ }^{1} \mathrm{H}$ NMR and ${ }^{13} \mathrm{C}$ NMR analysis.

\section{References}

1. Huang C, Tang X, Fu H, Jiang Y and Zhao Y 2006 Proline/Pipecolinic Acid-Promoted Copper-Catalyzed P-Arylation J. Org. Chem. 715020

2. Huang C, Fu Y, Fu H, Jiang Y and Zhao Y 2008 Highly efficient copper-catalyzed cascade synthesis of quinazoline and quinazolinone derivatives Chem. Commun. 47 6333

3. Tlili A, Xia N, Monnier F and Taillefer M 2009 A very simple copper-catalyzed synthesis of phenols employing hydroxide salts Angew. Chem. Int. Edit. 488725

4. Yang D and Fu H 2010 A Simple and Practical CopperCatalyzed Approach to Substituted Phenols from Aryl Halides by Using Water as the Solvent Chem. Eur. J. 16 2366

5. Zhang Y-H and Yu J Q 2009 Pd(II)-Catalyzed Hydroxylation of Arenes with 1 atm of $\mathrm{O}_{2}$ or Air J. Am. Chem. Soc. 13114654
6. George T, Mabon R, Sweeney G, Sweeney J B and Tavassoli A J 2000 Alcohols, ethers and phenols Chem. Soc. Perkin Trans. 12529

7. Cohen T, Dietz A G and Miser J R 1977 A simple preparation of phenols from diazonium ions via the generation and oxidation of aryl radicals by copper salt $\mathrm{J}$. Org. Chem. 422053

8. Dumrath A, Wu X F, Neumann H, Spannenberg A, Jackstell R and Beller M 2010 Angew. Chem. Int. Edit. 49 8988

9. Schulz T, Torborg C, Schaffner B, Huang J, Zapf A, Kadyrov R, Borner A and Beller M 2009 Practical Imidazole-Based Phosphine Ligands for Selective Palladium-Catalyzed Hydroxylation of Aryl Halides Angew. Chem. Int. Edit. 48918

10. Ren Y L, Cheng L, Tian X Z, Zhao S, Wang J and Hou C 2010 Iron-catalyzed conversion of inactivated aryl halides to phenols in water Tetrahedron Lett. $\mathbf{5 1} 43$

11. Jing L, Wei J, Zhou L, Huang Z, Li Z and Zhou X 2010 Lithium pipecolinate as a facile and efficient ligand for copper-catalyzed hydroxylation of aryl halides in water Chem. Commun. 464767

12. Zhao D, Wu N, Zhang S, Xi P, Su X, Lan J and You J 2009 Synthesis of phenol, aromatic ether, and benzofuran derivatives by copper-catalyzed hydroxylation of aryl halides Angew. Chem. Int. Edit. 488729

13. Yang K, Li Z, Wang Z, Yao Z and Jiang S 2011 Highly Efficient Synthesis of Phenols by Copper-Catalyzed Hydroxylation of Aryl Iodides, Bromides, and Chlorides Org. Lett. 134340

14. Thakur K G and Sekar G 2011 D-Glucose as green ligand for selective copper-catalyzed phenol synthesis from aryl halides with an easy catalyst removal Chem. Commun. 476692

15. Paul R, Ashif M d Ali and Punniyamurthy T 2010 Copper-Catalyzed Hydroxylation of Aryl Halides with Tetrabutylammonium Hydroxide: Synthesis of Substituted Phenols and Alkyl Aryl Ethers Synthesis 244268

16. Sheldon R A 2000 Atom efficiency and catalysis in organic synthesis Pure Appl. Chem. 721233

17. Monnier F and Taillefer M 2009 Catalytic C[BOND]C, $\mathrm{C}[\mathrm{BOND}] \mathrm{N}$ and $\mathrm{C}[\mathrm{BOND}] \mathrm{O}$ Ullmann-Type Coupling Reactions Angew. Chem. Int. Edit. 486954

18. Bradley D C, Mehrotra R C, Rothwell I P and Sing 2001 Alkoxo and Aryloxo Derivatives of Metals (London: Academic Press London) 